\title{
The Anthropomorphized Emotional Profile of a (Un) Healthy Tooth
}

\author{
Maria do Rosario Dias, PhD \\ Samir Ahmad, PhD \\ Helcília Dias dos Santos, \\ Maria Calejo Pires, \\ Ana Ferreira, $M A$ \\ Valter Alves, $M A$ \\ Ana Delgado, PhD
}

Egas Moniz-Cooperativa de Ensino Superior, CRL, Monte de Caparica, Portugal

Doi:10.19044/esj.2020.v16n26p1 ～URL:http://dx.doi.org/10.19044/esj.2020.v16n26p1

\begin{abstract}
Drawing as a projective technique allows the access to the child's intrapsychic experiences. Notoriously, the use of drawings has been known as a referential research instrument in qualitative Health studies. Objectives: This exploratory study aims at understanding the mental representation of the concept of a healthy tooth and of an unhealthy tooth, through anthropomorphized drawings made by children, aged 6-12 years. Methods: The sample consisted of 150 children of both genders who attended at least one dental appointment at a University Dental Clinic of a metropolitan urban area. Drawings that showed anthropomorphized teeth $(n=300)$ were selected to perform the content analysis of the anthropomorphized features. Results: There is a clear variation in the level of anthropomorphizing of teeth according to age and gender. Conclusion: The results point to an increase in subject's mental representation of reality in drawings in accordance to subject's age, most significantly from 10 years onwards.
\end{abstract}

Keywords: Oral health, Mental and Pictorial Representation, Caries, Anthropomorphized Drawings, (Un) Healthy Teeth

\section{Introduction}

Children need to constantly create psychically charged meaning systems to decodify the world around them, resorting to symbolic thinking. For children, symbolic language is supported by the use of drawings, to the 
detriment of verbal language (Dias \& Simões, 2016; Dias, Santos, Naben, \& Ventura, 2019). The use of drawings as an instrument for expression of feelings and emotions as a projective technique has been referred to as a preferred research instrument in qualitative health studies (Dias \& Simões, 2016; Dias et al., 2019). This projective technique allows to establish a bridge to children's intrapsychic experiences, who still have little affective-emotional maturity and difficulty in transmitting their ideas verbally, or by any other means of expression (Byrne, 2009; Pereira, 2010).

One of the fundamental characteristics of children's drawings, analytically speaking, is the fact that they seem to represent more what they know about a significant object (imago), rather than what they visually perceive of it. The drawing thus surpasses the mental replica of a mere visual image, insofar as it mirrors the (pre) conception of the object itself, that is, its meaning/ signifier (Dias et al., 2019; Pereira, 2010).

Additionally, drawing as a projective technique, is a tool used in several empirical fields, insofar as it allows a gateway to the inter and intrapersonal thinking processes of children and to the communication of their inner most hidden emotions (Cariota, 2006; Ribeiro \& Pinto-Junior, 2009). As Dolto (2014) pointed out, a drawing is not self-explanatory, it is the child that explains herself through the drawing. This reasoning has aroused a methodological interest in contemporary researchers to use children's drawings as a referential instrument, namely with samples of subjects under school age (Dias \& Simões, 2016; Rodrigues, Ortiz \& Bienert, 2004).

Thus, drawings are a non-verbal communication tool used by children's psychology scholars to access the emotional bonds experienced by children (Chernoff, 1973; Dias \& Neves, 2016; Magalhães, Alvarenga, \& Nina-e-Silva, 2013). In fact, long before children are able to communicate their feelings and thoughts by words, they are able to express their conscious and unconscious attitudes, as well as their desires and concerns by drawings, a remarkable instrument for depicting affective relationships in this target population (Dias et al., 2019; Reis, Dias, \& Leal, 2008; Reis, Dias \& Leal, 2011; Rodrigues, Ortiz, \& Biernet, 2004; Wechsler \& Schelini, 2002).

According to the current scientific literature, what the child thinks, and feels is extremely relevant in the latency stage. Hence, qualitative methodologies such as the use of drawings as a projective technique (also called "child-centered research") are considered appropriate to depict the child's inner experience (Dias et al., 2019; Ferreira, 2002). Hence, drawings are the child's main form of cognitive and emotional expression in the latency stage, which is in itself a universal form of language (Dias \& Simões, 2016).

The presence of anthropomorphized drawings in children, with the attribution of human characteristics to inanimate objects, is a tool to transmit metaphorical messages through emotional expressions or facial human traits, 
such as smiles or tears (Daston \& Mitman, 2006; Dias \& Simões, 2016; Guthrie, 1993; Mitchell, Thompson \& Miles, 1997; Serpell, 2005; Torres, 2009;).

The anthropomorphism is thus defined as the attribution of human characteristics or behaviors to a non-human entity and covers phenomena as diverse as attributing thoughts and emotions to domestic or wild animals (Fisher, 1991; Kracher, 2002; Urquiza-Haas \& Kotrschal, 2015). Although the genesis of anthropomorphism is unknown, it can be defined as the attribution of physiological, human and/or behavioral characteristics to non-human animals or inanimate objects, and it has been used under this scope in the present study, in which children have resorted to anthropomorphized drawings as a means of depicting a healthy tooth and an unhealthy tooth (Dias \& Simões, 2016). Anthropomorphism can also go beyond animism, as it attributes motivations, emotions and cognitive abilities considered typically human to animals or non-human objects (Magalhães, Alvarenga \& Nina-E-Silva, 2013; Urquiza-Haas \& Kotrschal, 2015; Waytz, Cacioppo, \& Epley, 2010; Waytz, Heafner, \& Epley, 2014).

Therefore, the present study focused on the content analysis of anthropomorphized drawings of inanimate objects, namely of human teeth, in particular on what is children's mental representation of the image of a healthy tooth and of an unhealthy tooth. It was assumed that the content analysis of these anthropomorphized drawings could elicit differences to children's internalized mental representations of what were healthy and unhealthy teeth. Furthermore, these expected differences allowed to create objective pictorial profiles of what constituted a healthy tooth and an unhealthy tooth.

\section{Methods}

For this research, a mixed method research approach was selected, in which researchers collected and analyzed both quantitative and qualitative data within the same study. This exploratory study aimed at understanding the mental representation of the concept of a healthy tooth and of an unhealthy tooth, through anthropomorphized drawings made by children, aged 6-12 years. For such, a sample of 150 children of both genders was considered. These children attended at least one dental appointment at a University Dental Clinic of a metropolitan urban area. Drawings that showed anthropomorphized teeth were selected $(n=300)$ to perform the content analysis of the anthropomorphized features.

\section{Participants}

The sample for this study comprehended a total of 150 school-aged children of both genders (65.3\% girls; $34.7 \%$ boys), distributed according to six age-groups, from 6 to 12 years of age (Figure 1). 


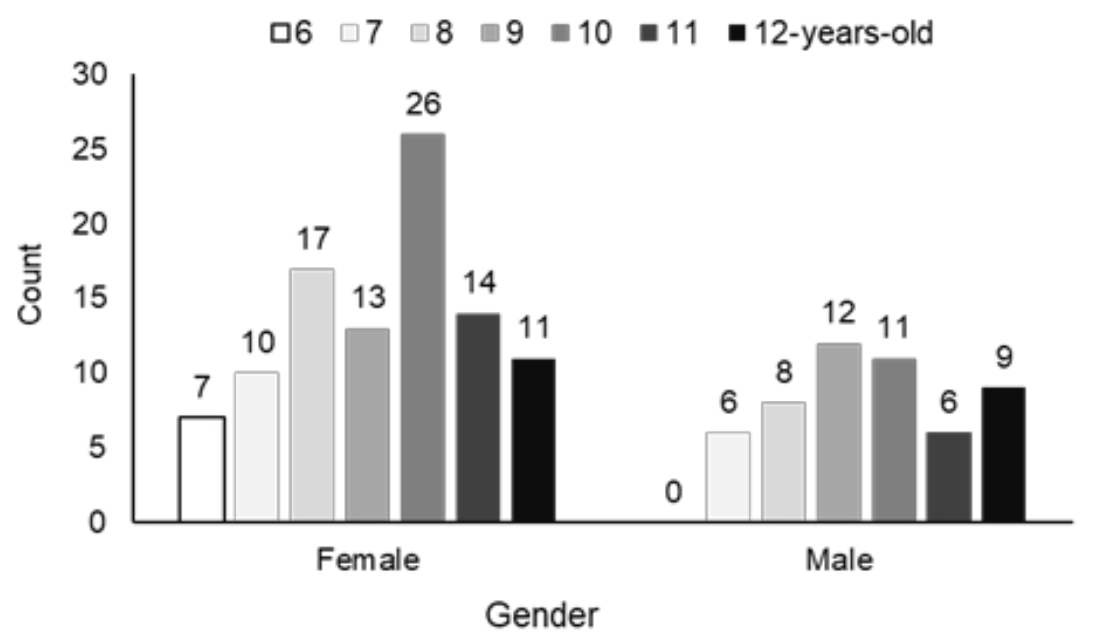

Figure 1: Relationship between age (6-12 years) and gender of subjects

\section{Instruments}

Patients were invited to produce two drawings (pictorial representation protocols) depicting a healthy tooth and an unhealthy tooth. These drawings consisted of two A4 sheets, one in which children drew their illustrations with graphite pencils.

In addition, all participants answered a socio-demographic inquiry regarding the child's age, gender, and school grade.

A qualitative content grid for the analysis of the 300 drawings was originally designed to study the pictorial representations found in the sample, with seven categories: symbolism $(\mathrm{C} 1)$; details $(\mathrm{C} 2)$; size of the drawing $(\mathrm{C} 3)$; perspective of the drawing (C4); general appearance of the teeth (C5); anthropomorphized drawing (C6) and accessories (C7), which encompassed 13 additional analytical subcategories.

\section{Procedures}

Data were collected in two distinct consecutive moments: (i) each child was initially asked to draw a healthy tooth in the first sheet of paper and to draw an unhealthy tooth in the second sheet of paper; (ii) once both pictograms were finished, the child was asked three questions aimed at determining their mental representation of the healthy tooth, of the unhealthy tooth and of tooth decay (Dias \& Simões, 2016). Drawings were then labeled according to the child's answers, whenever necessary for complementary understanding.

Quantitative data were analyzed using SPSS (Statistical Package for the Social Sciences), version 19.0 for Windows. All the procedures were approved by the Ethics Committee of the Institution where protocols were collected. 


\section{Results}

Results obtained allowed to verify that there was a larger number of protocols with drawings elaborated by girls $(65.3 \% ; \mathrm{n}=98)$ rather than by boys $(34.7 \% ; \mathrm{n}=52)$. Despite this asymmetry, girls seem to have resorted more to the pictorial anthropomorphizing of the drawings.

Also, in terms of age, there was a predominance of 10-year-old children (24.7\%), who resorted to anthropomorphized drawings, in comparison to the reduced number of 6-year-old children that did the same $(4.7 \%)$. This second finding was of added importance with regards to the analysis of results and justification of the conclusions obtained in the present study.
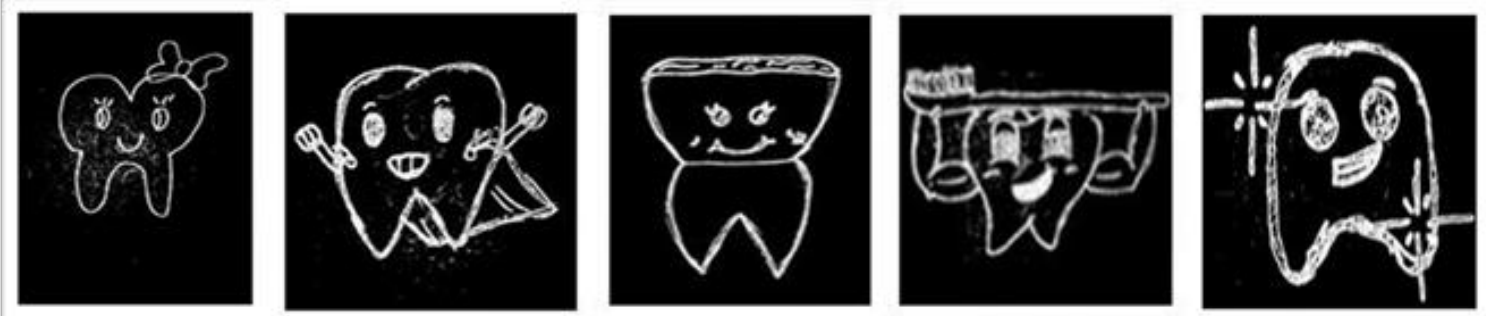

Figure 2: Anthropomorphized drawings representing the profile of a healthy tooth

The healthy tooth pictorial representation (Figure 2) revealed in $94 \%$ of the cases a one-dimensional (2D), a single tooth (93.3\%), big in size (45.3\%) and anthropomorphized with an unrealistic shape (92.0\%). Generally, the drawings showed happy faces $(89.1 \%)$, with eyes, noses, and mouths. They also showed a clean tooth, characterized by the absence of spots, holes or fractures (Dias et al, 2019). Typically, accessories that were depicted in the drawings included a toothbrush $(7.3 \%)$, a toothpaste $(2.7 \%)$, hair ribbons $(4.7 \%)$, a superman cape $(2.7 \%)$, dumbbells $(1.3 \%)$ or stars and glitter $(12.7 \%)$. These added teeth accessories indicate that children associate a clean tooth to a strong, fit tooth. Interestingly, some children added to the oral cavity drawings a tongue $(3.3 \%)$, jaws $(1.3 \%)$ and gums $(0.7 \%)$.

The unhealthy tooth pictorial representation (Figure 3 ) revealed in $95.3 \%$ of the cases a one-dimensional (2D), a single tooth $(94.7 \%)$, normal in size $(48 \%)$ and anthropomorphized with an unrealistic shape $(82.7 \%)$, often with tears on it $(12.7 \%)$. The unhealthy tooth was characterized by the presence of holes $(17.3 \%)$, fractures $(19.3 \%)$ and spots of medium size (31.3\%). Typically, accessories that were depicted in the drawings included animals or bugs $(7.3 \%)$, thermometers $(7.3 \%)$ and band aids $(5.3 \%)$. These added teeth accessories indicate that children associate an unhealthy tooth to a non-septic tooth.

Interestingly, some children added to the oral cavity drawings a tongue $(1.3 \%)$ and gums $(1.3 \%)$, just as in the healthy tooth drawings. 

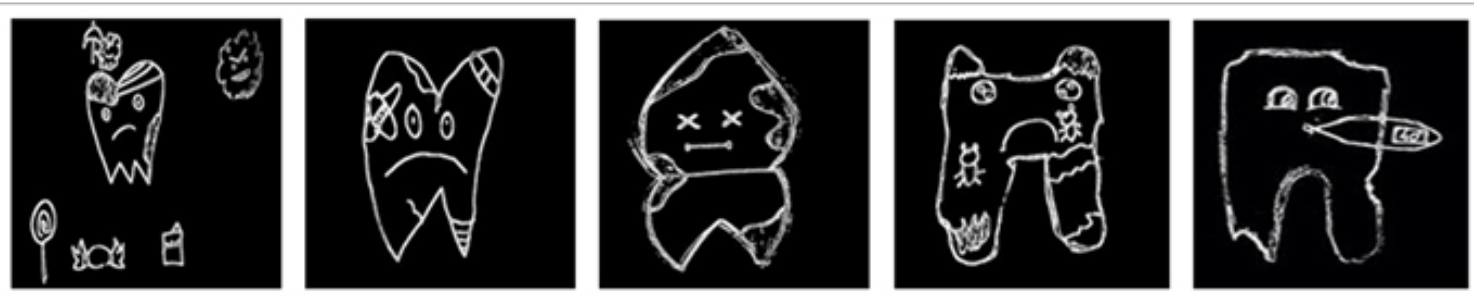

Figure 3: Anthropomorphized drawings representing the profile of an unhealthy tooth

\section{Discussion}

Across all drawings, the anthropomorphized profile of a human face that is connected to the mental representation of a healthy tooth is drawn with eyes $(100 \%)$, nose $(12.1 \%)$, a happy smile $(95.7 \%)$ - or in minority of cases with a neutral smile (3.6\%) and eyebrows $(6.4 \%)$. Occasionally, in the happy smile feature, the exposure of the dental arches is evident, and the smile itself contains drawn teeth $(11.4 \%)$.

In contrast, the mental representation of an unhealthy tooth is drawn with eyes (97.2\%), a sad smile (95.7\%), nose (8.3\%), neutral smile (7.6\%), eyebrows $(4.2 \%)$ and tears $(12.7 \%)$.

In the profile representing the healthy tooth, it was observed that $12.1 \%$ of children drew the full human face (eyes, nose, and mouth), against $6.9 \%$ in the unhealthy tooth profile. In both profiles, it was possible to detect the emotional expression of the face, fundamentally based on the curvature of the smile (Magalhães, Alvarenga \& Nina-E-Silva, 2013), which is also in line with Chernoff's theory (Chernoff, 1973) (Figure 4). 


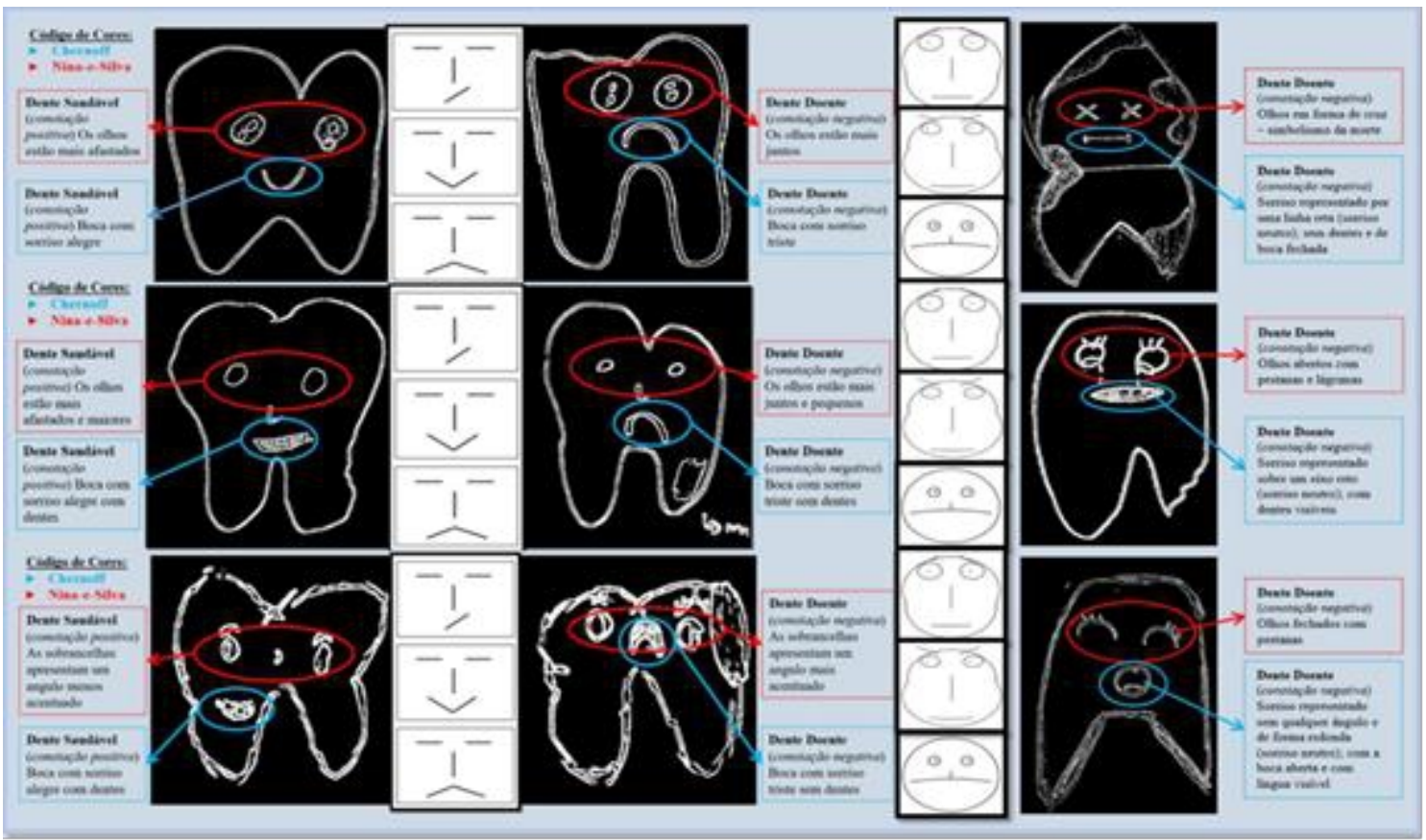

Figure 4: Anthropomorphized profiles of healthy and unhealthy teeth depicting eyes and mouth according to Magalhães, Alvarenga \& Nina-E-Silva (2013), and Chernoff (1973). The white left column depicts anthropomorphized tooth symbology of Magalhães, Alvarenga \& Nina-E-Silva (2013), and the white right column depicts anthropomorphized tooth symbology of Chernoff (1973). Examples of the first and second authors were found in the present study's drawings (marked with red and blue ovals respectively).

The healthy tooth proved to be more invested in terms of the size category, since it tended to be larger, with more details, with a smile denouncing more emotional traits, when compared to the tooth represented as an unhealthy tooth.

With regards to the healthy tooth, it seemed to be perceived by most children as a tooth free of dental caries, stains or fractures; it is characterized as a white and clean tooth, often accompanied by the star and glitter symbols. The healthy tooth profile also presented a positive mental representation for most children, possibly associated to the anthropomorphizing of teeth and to the attribution of humanized anatomical and physiological traits to teeth (such as eyes, nose, mouth, hands, and legs). It can also be formulated that in general children resorted preferably to the depiction of anthropomorphized eyes and mouth to convey human emotions.

In fact, the healthy tooth was associated with positive emotions, namely by the representation of a happy smile. Contrary, the unhealthy tooth was negatively connoted, namely by the representation of physiological traits that transmitted negative emotions, such as a sad smile or an open, surprised looking mouth. The unhealthy tooth profile was also associated to the 
depiction of tears, as a form of expression of sadness, fear or even pain and discomfort.

When comparing healthy and unhealthy teeth profiles, neutral smiles were observed in both cases (Figures 2 and 3), except for the 6 years age group in the healthy and unhealthy tooth profiles and the 12 years age group in the healthy tooth profile.

\section{Conclusion}

In both healthy and unhealthy tooth profiles was possible to recognize the depiction of the emotional expression of a human face, fundamentally by the curvature drawn in the smile category. Indeed, in the healthy tooth profile the smile denounced notoriously emotional traits of joy, in clear opposition to the unhealthy tooth profile, in which tears falling down the face were highlighted, as well as sad or neutral smiles.

There also seems to exist a clear fluctuation in anthropomorphizing levels according to age and gender. Results point to an increase in subject's mental representation of reality in drawings in accordance with the child's chronological age, most significantly from 10 years on. At this age, children seem to be able to (re)elaborate their thinking, as well as to resort to fundamental logic.

Generally, subjects categorize healthy teeth with a well-defined outline and with white coloring, in contrast to unhealthy teeth that seem to be perceived as decayed, presenting dental caries, stains, fractures and sometimes depicting the presence of bacteria (bugs) as well as ice bags, foul odors, hospital beds, thermometers and canes.

It should also be noted that, despite the asymmetry in terms of sample size regarding the female gender, girls seem to have resorted more to the pictorial anthropomorphizing of the drawings.

The ability for realistic (pre)conceptualization seems difficult in children of the studied age groups regarding their intrapsychic functioning, as well as the projection of these experiences into a pictorial drawing. Thus, children seem to resort to the depiction of bipolarized emotions regarding healthy and unhealthy teeth, namely via a "good" or "bad" psychic object. In that same line, the emotions depicted regarding facial expressions, resort to the most intelligible way of representing emotions, representing joy and/or sadness.

\section{References:}

1. Byrne, J., Grace, M., \& Hanley, P. (2009). Children's anthropomorphic and anthropocentric ideas about micro-organisms: Educational research. Journal of biological education, 44(1), 37-43. 
2. Cariota, T. C. (2006). O Desenho da Figura Humana de crianças com bruxismo. Boletim de Psicologia, 124(56), 37-52.

3. Chernoff, H. (1973). The use of faces to represent points in $\mathrm{k}$ dimensional space graphically. Journal of the American statistical Association, 68(342), 361-368.

4. Costa, A. (2015). Children's perception of dentists through the interpretation of drawings. Brazilian Research in Pediatric Dentistry and Integrated Clinic, 15(1), 407-419.

5. Daston, L., \& Mitman, G. (2006). Thinking with animals: New perspectives on anthropomorphism. N. York: Columbia University Press.

6. Dias, M. D. R., Santos, A. C., Naben, L., \& Ventura, I. (2019). Dental decay in the change of deciduous teeth: The child's self-perception. EC Dental Science, 18, 2214-2220.

7. Dias, M. R., \& Neves, A. C. (2016). Mente Sã em Corpo São: Representação mental do corpo saudável e doente na criança. Omnia: Revista Interdisciplinar de Ciências e Artes, 4, 55-64.

8. Dias, M. R., \& Simões, N. P. (2016). On the mental representation of (un) healthy tooth: (un) healthy tooth profiles among children. Journal of Educational and Developmental Psychology, 6, 110-116.

9. Dolto, F. (2014). Lorsque L'Enfant Parait. Tomo 2. Paris: Points.

10. Ferreira, T. (2002). Em Defesa da Criança. Teoria e prática Psicanalítica da Infância. Lisboa: Assirio \& Alvim.

11. Fisher, J. A. (1991). Disambiguating anthropomorphism: An interdisciplinary review. Perspectives in ethology, 9(4).

12. Gobbi, M., \& Leite, M. I. (2002). O desenho da criança pequena: distintas abordagens na produção acadêmica em diálogo com a educação. Ata e desata: partilhando uma experiência de formação continuada. Rio de Janeiro: Ravil, 93-148.

13. Guthrie, S. (1993). Faces in the Clouds: A New Theory of Religion. New York: Oxford University Press.

14. Kracher, A. (2002). Imposing order - The varieties of anthropomorphism. Studies in Science and Theology, 8, 239-261.

15. Magalhães, L. M., Silva, C. H. N. E., \& Alvarenga, L. F. C. (2013). Atribuição de emoções a traços faciais artificiais. Revista da Universidade Vale do Rio Verde, 11(2), 462-469.

16. Mathur, J., Diwanji, A., Sarvaiya, B., \& Sharma, D. (2017). Identifying dental anxiety in children's drawings and correlating it with Frankl's behavior rating scale. International Journal of Clinical Pediatric Dentistry, 10(1), 24.

17. Mitchell, R., Thompson, N., \& Miles, L. (1997). Anthropomorphism, Anecdotes and Animals. New York: Suny Press. 
18. Pereira, L. D. T. K. (2006). O desenho infantil e a construção da significação: um estudo de caso. In World Conference on Arts Education: Building Creative Capacities for the 21st CenturyUNESCO, March 6-9, 2005, Lisbon, Portugal.

19. Reis, F., Dias, M. D. R., \& Leal, I. (2008). A consulta no setting odontopediátrico: A percepção subjectiva do medo. Análise Psicológica, 26(2), 239-250.

20. Reis, F., Dias, M. R., \& Leal, I. (2011). A representação mental da consulta de odontopediatria com o recurso ao desenho. Teixeira JAC. Comportamento e Saúde. Lisbon, Portugal: ISPA, 155-76.

21. Ribeiro, C. R., \& Pinto-Junior, A. A. (2009). A representação social da criança hospitalizada: Um estudo por meio do procedimento de desenho-estória com tema. Revista da SBPH, 12(1), 31-56.

22. Rodrigues, M., Ortiz, C., \& Bienert, M. D. (2004). Percepções de saúde e educação para a saúde de crianças com recurso ao método "desenho/escrita". In Actas do $5^{\circ}$ Congresso de Psicologia da Saúde. Lisboa: Sociedade Portuguesa de Psicologia da Saúde. Resumo (p. 122).

23. Schilhab, T. S. (2002). Anthropomorphism and mental state attribution. Animal Behaviour. doi:10.1006/anbe.2002.2001

24. Serpell, J. (2005). People in disguise: Anthropomorphism and the human-pet relationship. (121-136). N. York: Columbia University Press.

25. Torres, S. (2009). O Antropomorfismo e a Pintura. Um Exemplo: o Cão. Tese Doutoramento, Universidade do Porto, Porto.

26. Urquiza-Haas, E. G., \& Kotrschal, K. (2015). The mind behind anthropomorphic thinking: attribution of mental states to other species. Animal Behaviour, 109, 167-176.

27. Waytz, A., Cacioppo, J., \& Epley, N. (2010). Who sees human? The stability and importance of individual differences in anthropomorphism. Perspectives on Psychological Science, 5(3), 219232.

28. Waytz, A., Heafner, J., \& Epley, N. (2014). The mind in the machine: Anthropomorphism increases trust in an autonomous vehicle. Journal of Experimental Social Psychology, 52, 113-117.

29. Wechsler, S., \& Schelini, P. W. (2002). Validade do desenho da figura humana para avaliação cognitiva infantil. Avaliaçao Psicologica: Interamerican Journal of Psychological Assessment, 1(1), 29-38. 